\title{
An Investigation Into The Mechanical Damping Characteristics Of Catenary Contact Wires And Their Effect On Aerodynamic Galloping Instability.
}

\section{T Stickland*, T J Scanlon, I A Craighead}

Department of Mechanical Engineering, University of Strathclyde, Glasgow, G1 1XJ

\section{J Fernandez,}

Mecanica de Fluidos, Universidad de Oviedo, Campus de Viesques, 33271 Gijón Spain

Keywords Galloping structures, wind tunnel, vibration, overhead line, contact wire, mechanical damping

\begin{abstract}
The measurement of the damped oscillation of a section of the UK East Coast Main Line (ECML) catenary/contact wire system has been undertaken and the natural frequency and mechanical damping were found to be $1.4 \mathrm{~Hz}$ and 0.05 respectively. This information was used to assess the effect of increasing the mechanical damping ratio on the susceptibility of the system to an aerodynamic galloping instability. The section of line tested was known to gallop at wind speeds of approximately $40 \mathrm{mph}$ and theoretical and experimental work verified this. A friction damper arm was designed and 3 units fitted to the section of line effected. The introduction of increased mechanical damping was found to raise the mechanical damping coefficient of the line to between 0.095 and 0.18 and the mathematical analysis produced a theoretical wind speed for galloping oscillation of between $75 \mathrm{mph}$ and $141 \mathrm{mph}$
\end{abstract}


respectively. For over a year, since the units were fitted, no problems with galloping instability have been observed.

\section{NOTATION}

\begin{tabular}{ll}
$\alpha$ & angle of attack \\
$\delta$ & log decrement \\
$\rho$ & density \\
$v$ & kinematic viscosity \\
$\zeta$ & damping ratio \\
$\omega$ & natural frequency \\
$\omega_{d}$ & damped natural frequency \\
$\omega_{n}$ & undamped natural frequency \\
$X_{n}$ & peak amplitude \\
$m$ & mass per unit length \\
$B$ & diameter of wire \\
$\mathrm{F}$ & restoring force \\
$C_{L}$ & lift coefficient \\
$C_{D}$ & drag coefficient \\
$d$ & damping coefficient \\
$\mathrm{t}$ & time \\
$\mathrm{T}$ & vibration period time \\
$U$ & wind speed \\
$u_{*}$ & shear velocity \\
$k$ & spring stiffness \\
$c$ & constant \\
$y$ & horizontal coordinate \\
\hline & vertical coordinate \\
\hline &
\end{tabular}




\section{INTRODUCTION}

It has been known for a long time, that there are problems associated with large amplitude oscillations in the overhead conductors at a number of locations on the East and West coasts of Scotland. Oscillating conductors have the potential to cause serious dewirements at the contact wire/pantograph interface, leading to delay and cancellation of services using the effected lines. In all cases it has been determined that, in high winds, the conductors display an aerodynamically induced, large amplitude, oscillation. Analysis of video film of these oscillations indicates that the oscillations are created by a phenomenon known as galloping.

Galloping is created by unsteady wind forces acting on an object. The unsteady forces are caused by the shape of the object generating asymmetric lift and drag forces which produce an undamped oscillation. A typical overhead line contact wire has a cylindrical shape with two side grooves to allow it to be supported by the catenary system as shown in figure 1. An alternative contact wire additionally has a small groove running along the top of the contact wire (also shown in figure 1). Stickland et $\mathrm{al}^{[1]}$ showed that the edges of these grooves, combined with flattening of the bottom of the conductor due to wear, produces the aerodynamic galloping phenomenon observed. For more information on galloping and aeroelastic phenomena in general the reader is referred to Sachs ${ }^{[2]}$ and Simiu ${ }^{[3]}$. Scanlon et al ${ }^{[4]}$ initially considered wind breaks and shelter belts as a cure for the galloping instability. However, due to physical constraints around the embankments upon which the overhead conductors exhibit the galloping instability, it was not practical to construct the shelter belts suggested. Also, the modifications to the wire profile suggested by Stickland et al ${ }^{[1]}$ were not practical. A third means to address the problem was therefore sought. It was suggested that the generation of additional mechanical damping forces within the overhead conductor/catenery system would increase the wind speed at which aerodynamic galloping would occur. If the wind speed for incipient galloping could be increased to a level that is rarely seen, then the occurrence of galloping oscillations would be significantly reduced. 


\subsection{ONE DIMENSIONAL AERODYNAMIC GALLOPING}

Stickland et $\mathrm{al}^{[1]}$ explain the aerodynamic causes of the galloping instability and present the 1D equation of motion for this instability, equation 1.

$$
m\left[\ddot{y}+2 \zeta \omega \dot{y}+\omega^{2} y\right]=-\frac{1}{2} \rho U B\left(\frac{d C_{L}}{d \alpha}+C_{D}\right) \dot{y}
$$

The right hand side of this equation is the aerodynamic contribution to the overall system damping. Rearranging this equation ${ }^{[1]}$ and recognising that that the net damping coefficient, $d$, as:

$$
2 m \zeta \omega+\frac{1}{2} \rho U B\left(\frac{d C_{L}}{d \alpha}+C_{D}\right)=d
$$

If this damping coefficient is positive, the system is stable and, if it is negative, the system is unstable. Since the mechanical damping ratio, $\zeta$, is usually positive a system cannot gallop unless:

$$
\left(\frac{d C_{L}}{d \alpha}+C_{D}\right) \prec 0
$$

which is referred to as the Glauert - Den Hartog criterion.

A system will gallop if $\mathrm{d}<0$ and this will depend upon the above criterion being met, the mass and mechanical damping ratio being sufficiently small and the wind speed $U$ to be sufficiently high for $\mathrm{d}$ to meet the above criterion. When all these conditions are met then a galloping instability will occur.

Stickland et $\mathrm{al}^{[1]}$ undertook wind tunnel measurements to determine the Glauert-Den Hartog criterion for the contact wire cross section. The wind tunnel tests were undertaken at a Reynolds number of $1.3 \times 10^{5}$. Figure 2, shows this criterion for a new wire and differing amounts of wear to the lower surface. It may be seen that the contact wire, when new, will not gallop. However, with increasing wear, the wire will tend to gallop and the angle of incidence at which the wire will gallop decreases. 


\subsection{Calculation Of Wind Speed For Galloping}

Given the stability parameter it is interesting to calculate the wind speed required for the onset of galloping. The damping in the equation of motion is given by equation 2 . Rearranging this equation for $\mathrm{U}$, the wind speed, gives:

$$
U=\frac{d-2 m \zeta \omega}{\frac{1}{2} \rho B\left(\frac{d C_{L}}{d \alpha}+C_{D}\right)}
$$

Now, galloping will occur when $d$ is negative. Hence, if $d$ is set to zero in equation 4, the value of $U$ calculated is the wind speed above which galloping will occur, i.e.

$$
U=\frac{2 m \zeta \omega}{\frac{1}{2} \rho B\left(\frac{d C_{L}}{d \alpha}+C_{D}\right)}
$$

Stickland ${ }^{[1]}$ had to assume a value for the mechanical damping, $\zeta$, of the system as this was unknown at the time. However, by assuming a reasonable value for the mechanical damping it was shown that, at the correct angle of attack, it was possible for the contact wire to exhibit galloping in wind speeds as low as $19 \mathrm{mph}$.

The lack of success by Stickland et al in finding a cure for the galloping problem by either wind breaks ${ }^{[4]}$ or modifications to the contact wire cross section ${ }^{[1]}$ caused the authors to consider modifying the mechanical damping of the contact wire/catenery system. The theoretical work by Stickland et $\mathrm{al}^{[1]}$ suggested that increasing the mechanical damping of the system would increase the wind speed at which galloping could occur.

\section{MEASUREMENT OF SYSTEM DAMPING}

\subsection{Theory}

Although the contact wire/catenery is a distributed parameter system, it can be approximated as a single degree of freedom system if it is only the first mode of 
vibration that is of interest. For a single degree of freedom system, shown in Figure 3, the equation of motion can be written as;

$$
m \ddot{x}=-k x-c \dot{x}
$$

assuming that no external forces act. Solution of equation 6 results in :-

$$
x=A e^{-\sigma t} \sin \left(\omega_{d} t+\phi\right)
$$

where A and $\phi$ are constants which depend on the initial conditions. $\sigma=c / 2 \mathrm{~m}$ and $\omega_{\mathrm{d}}$ is the damped natural frequency of the system which, for lightly damped cases, is almost the same as the undamped natural frequency $\omega_{\mathrm{n}}$. The damping ratio is defined as:-

$$
\zeta=\frac{\sigma}{\omega_{n}}=\frac{c}{2 \sqrt{k \cdot m}}
$$

The level of damping in a structure can be conveniently measured by exciting the structure and measuring its response. The most convenient form of excitation is an impulse where the ensuing vibration signal decay is measured. Figure 4 shows a typical trace. At each peak the sine term in equation 7 must be equal to 1 and the amplitude of the peak is given by:-

$$
\begin{aligned}
& X_{0}=A e^{-\sigma(0)} \\
& X_{1}=A e^{-\sigma(1)}=A e^{-\sigma(t(0)+T d)}=X_{0} e^{-\sigma T d} \\
& X_{2}=A e^{-\sigma(2)}=A e^{-\sigma(t(0)+2 T d)}=X_{0} e^{-\sigma 2 T d} \\
& \text { etc. }
\end{aligned}
$$

After $n$ cycles

$$
X_{n}=X_{0} e^{-\sigma n T d}
$$

The terms $\sigma \mathrm{Td}$ is referred to as the log decrement $\delta$ and gives a measure of the damping in the system.

$$
X_{n}=X_{0} e^{-n \delta}
$$

or rearranging :-

$$
\delta=\frac{1}{n} \ln \frac{X_{0}}{X_{n}}
$$

and the log decrement is related to the damping ratio

$$
\delta=\frac{c 2 \pi}{2 m \omega_{d}}=\frac{2 \pi \zeta}{\sqrt{\left(1-\zeta^{2}\right)}}
$$


which, for lightly damped systems, can be simplified to

$$
\delta=2 \pi \zeta
$$

Measurement of successive amplitudes of the vibration signal enables the log decrement to be determined and hence the damping ratio to be calculated. If the log of the amplitudes of successive cycles of the motion are plotted as a function of the cycle number the slope of the graph equals the log decrement for a linear system with viscous damping. If the damping is largely structural or hysteretic damping then the slope of the line will decrease with the number of cycles whereas, if friction is the dominant dissipative force, then the slope increases with the number of cycles. Oscillation of the slope would indicate that the damping is different in each direction of motion.

\subsection{Instrumentation}

Because of the relatively large amplitudes of motion and the low frequencies involved, draw string potentiometers were utilised to measure the displacement of the contact and support catenary wire. The effect of draw string potentiometers on the recorded damping was assessed to be minimal. For a typical tension of $11,300 \mathrm{~N}$ in the wire the addition of $30 \mathrm{~N} / \mathrm{m}$ from each draw string increased the stiffness by $5 \%$ resulting in an increase in natural frequency of $2.2 \%$ and was considered to be negligible. For a tension of $17350 \mathrm{~N}$ the effect of transducer loading is reduced further.

The other influence, which the transducer may impose, was frictional damping as the wire feeds in and out of the transducer housing. It was not possible to quantify the magnitude of this effect and it should be remembered that any figures for the damping in the system will include this contribution although it was considered to be small. Therefore the damping ratios obtained are likely to be a slight overestimate of the real damping in the system.

The transducer range was $0-1 \mathrm{~m}$ and the potentiometers were powered by a $10 \mathrm{v}$ laboratory power supply. The voltage output was therefor $0 \mathrm{v}$ for 0 displacement and $10 \mathrm{v}$ for $1 \mathrm{~m}$ displacement. The signals from the transducers were fed to a TEAC digital data recorder on channels 1 and 2. Channel 1 recorded data from the transducer 
connected to the support catenary and channel 2 recorded data for the conductor wire. Recordings of the measurements were made and the tape played back through a PC based data acquisition system for analysis

Measurements of the dynamic behaviour of the catenery/contact wire systems were made at night with no rain and a moderate wind. The temperature was approximately $10^{\circ} \mathrm{C}$. A mobile hydraulic trolley was used to provide a stable platform approximately $0.5 \mathrm{~m}$ below the contact wire. Test locations were identified as follows :-

Location 1 - approximately mid span on the span to the north of support

Location 2 - approximately $1 / 4$ span north of support.

Location 3 - at the support.

Location 4 - approximately $1 / 4$ span south of support

Location 5 - approximately mid span south of support.

At each location the transducer bar was clamped onto the platform directly beneath the cables using a G clamp. The draw strings were attached to each cable such that when the cables were stationary the draw strings were extended by approximately $350 \mathrm{~mm}$. The power supply was set to $10 \mathrm{v}$ and the output from each transducer was connected to the tape recorder inputs. Channel 1 recorded data from the support catenary vibration and channel 2 from the conductor wire. For each measurement, the conductor cable was forced downwards by 2 operators until the transducer draw strings were almost at zero and then the cable was quickly released. The ensuing vibration was then recorded until it died away. At each location 4 or 5 tests were conducted. Figure 5 shows the instrumentation set up during the measurement process.

\subsection{RESULTS}

\subsection{Results - original catenery/contact wire}

Figure 6 shows the typical response curve for a test and figure 7 shows a typical plot of the $\ln$ of amplitude against cycle number. Calculation of the slope of this line 
allows the log decrement to be determined and hence the damping ratio. From figure 7 it may be seen that the log plots did not produce a straight line as expected for a linear system. This was considered to be due to non-linearities (friction) that had been introduced into the system. The traces, therefore, required some interpretation in order to determine the damping ratio of the system. The solid line is a line plotted through the first two points and the dashed line is a line of best fit through all the points. It was thought that the first and second points, representing the initial displacement and the first overshoot, were the most accurately measured points but would give the most optimistic assessment of the damping ratio. Whilst the line of best fit would give pessimistic result. Calculated values of damping ratio and measured natural frequency of the system may be seen in table 1 .

\subsection{Addition of Mechanical Damping}

Figure 8 shows a one degree of freedom system with additional frictional damping The equation of motion for the system is:-

$$
m x=-k x-c x \pm F
$$

$\mathrm{F}$ acts in the opposite direction to the velocity of the mass to resist motion. Usually, the magnitude of $\mathrm{F}$ is assumed to be constant, which is acceptable for large amplitude vibration. At zero velocity, the friction force is able to increase to oppose motion until the limiting friction force is achieved. Any further increase in the applied force will then cause motion to occur. Equation 13 is non linear and thus the easiest means of obtaining a solution is to simulate its behaviour by evaluating the forces acting at small time intervals throughout the period of interest.

The equation was modeled in TUTSIM, a PC based simulation package, to investigate the effect of adding friction to the system. In section 3.1 it was shown that the following parameters are applicable to the equivalent single degree of freedom system; mass, $\mathrm{m}=14.6 \mathrm{~kg}$, stiffness, $\mathrm{k}=1130 \mathrm{~N} / \mathrm{m}$ and natural frequency, $\omega_{\mathrm{n}}=1.4$ Hz. Theoretically the frictional force could be engineered to any value. However, the greater the friction force the larger will be the contact force between the cable and the pantograph when a train passes. Also the cable will not return to the original equilibrium position as it will be restrained by an excessive friction force. The maximum value of this offset will be equal to the friction force divided by the 
stiffness of the equivalent spring. In general it will be less than this value, the precise value depending on the disturbance applied to the system. If a potential maximum offset of $\pm 20 \mathrm{~mm}$ was considered acceptable, then the friction force could be up to $1130 \times 0.020=22.6 \mathrm{~N}$. It should be noted that this force is not the vertical pantograph force but the maximum force possible in the damper which will produce a maximum of $20 \mathrm{~mm}$ fixed displacement in the contact wire.

Three cases were modelled by TUTSIM: For an initial displacement of $400 \mathrm{~mm}$ the simulation was run for 10 seconds with zero friction, with $11.3 \mathrm{~N}$ and $22.6 \mathrm{~N}$ friction forces. The time displacement histories were calculated, the log decrement determined and hence the theoretical mechanical damping of the system was calculated. The TUTSIM analysis showed that, for a friction force of $22.6 \mathrm{~N}$, the system damping would increase threefold and result in a possible cable height variation of $\pm 20 \mathrm{~mm}$. It was concluded that a pre-tensioned bolt, clamping the support arm to the support frame, would seem to be the easiest way of providing the required friction. Figure 9 shows a schematic of the final design of the mechanical damper and figure 10 shows the prototype damper in situ on a support arm.

\subsection{Results - increased damping}

Table 3 shows the damping ratios and natural frequency for the system with the mechanical Damper installed.

\subsection{DISCUSSION}

It may be seen from table 1 that Stickland' ${ }^{[1]}$ original estimate of $\omega=1.352 \mathrm{~Hz}$ for the natural frequency of the system was reasonable when compared with the measured natural frequency of approximately $1.4 \mathrm{~Hz}$. However, the estimate for the damping ratio of 0.1 would appear to be optimistic compared to the real, measured, damping ratio of 0.05 It is interesting to analyse the effect of this low rate of mechanical damping on the wind speed required for the onset of galloping. The results of this comparison for a cable tension of $11,300 \mathrm{~N}$ may be seen in table 4 . 
These results would indicate that the system is prone to a galloping instability at wind speeds as low as $10 \mathrm{mph}$. However it should be noted that instability at such low wind speeds can only occur at very high angles of attack. At low angles of attack, a Glauert Den-Hartog criterion of approximately -1 results, indicating a galloping onset speed of approximately $40 \mathrm{mph}$ which is in line with observations of the wind speeds at which galloping occurred in the real life system.

It is interesting to note that the amplitude of displacement in figure 6, measured without the extra mechanical damping, whilst originally decaying, remains at constant amplitude as a gust of wind passes over the wire. The gust speed was estimated at between 6.7 and $8.9 \mathrm{~m} / \mathrm{s}$ resulting in a displacement was approximately $60 \mathrm{~mm}$ thus indicating the tendency of the system to gallop at slightly higher wind speeds.

With the introduction of the frictional damper into the original system the increased mechanical damping had a significant effect on the galloping onset wind speed as shown in table 4. The estimate of the new mechanical damping of 0.095 indicated an increase in the galloping onset wind speed, at low angles of attack, from $40 \mathrm{mph}$ to 75 mph. The mechanical damping of 0.095 represented a pessimistic analysis of the data. An optimistic analysis yielded 0.18 and would give a galloping onset wind speed of $141 \mathrm{mph}$. The $75 \mathrm{mph}$ corresponds to gust speeds in gale force winds (47-72 $\mathrm{mph}$ ) whilst the higher speed of $141 \mathrm{mph}$ corresponds to wind speeds in excess of hurricane force (82mph).

Three of the dampers were manufactured and installed on the East Coast Main line in January 2001. After over one year of operation no de-wirements or galloping problems had been reported. Previously between 7 and 12 incidents occurred each year at this site, resulting in significant costs to the operating company and potential delays to passengers.

\section{CONCLUSIONS}

The authors have successfully measured the mechanical damping coefficient of the overhead catenary/conductor system on a section of the British East Coast Main Line. 
This has shown that the original value for the damping coefficient used by Stickland et al was optimistic and that, with a more realistic value, the wind speeds at which galloping might occur in a worn contact wire are much lower than originally predicted.

The authors have designed, built, installed and tested a device that increases the mechanical damping in the overhead catenary/contact wire which has significantly increased its mechanical damping. With the new mechanical damping device installed the wind speed, at which galloping might occur, has been raised to the equivalent of gusts from storm force winds and above and may be as high as hurricane levels. These wind speeds are extremely rare in the UK.

In the year following installation of three of the friction dampers no report of problems resulting from galloping have been received.

\section{ACKNOWLEDGEMENTS}

The authors would like to express their gratitude for the financial support provide by Railtrack PLC for this study and to Mr. J Vickers and Mr. R MacDonald for their advisory roles in the project

\section{REFERENCES}

[1] Stickland, M., Scanlon T, An Investigation Into The Aerodynamic Characteristics of Catenary Contact Wires in a Cross-Wind. Proceedings of the IMechE, Part F, Journal of Rail and Rapid Transport, vol 215 No. 4 pp 311-319 ISSN 0954-4097

[2] Sachs, Wind Forces in Engineering, Pergamon Press, 1978, ISBN 0080212999

[3] Simiu, E. and Scanlan, R.H. Wind Effects on Structures, Wiley Interscience, 1996

[4] Scanlon T, Stickland M, Oldroyd A, "An Investigation Into The Use of Windbreaks for the Reduction of Aeroelastic Oscillations of Catenary/Contact 
Wires in a Cross Wind". Proceedings of the IMechE, Part F, Journal of Rail and Rapid Transport, Vol 214, pp 173-182, 2000

[5] Li Q.S., Fang J.Q., Jeary A.P., "Evaluation of 2D coupled Galloping Oscillations Of Slender Structures”. Computers and Structures, Vol 66, No. 5, pp513-523, 1998.

[6] Matsumoto M., Daito Y., Yoshizumi F., Ichikawa Y., Yabutani T., "Torsional Flutter of Bluff Bodies" Journal of Wind engineering and Industrial Aerodynamics, 69-71 (1997) pp871-882

[7] Chabart O., Lilien J.L., "Galloping of Electrical Lines In Wind Tunnel Facilities", Journal of Wind Engineering and Industrial Aerodynamics, 74-76 (1998) pp967-976 


\section{List of Figures}

Figure 1: Contact wire cross section

Figure2: Glauert-Den Hartog Criterion

Figure 3: Single degree of freedom system

Figure 4: Typical vibration trace

Figure 5: Displacement transducers connected to overhead wires

Figure 6: Displacement $(/ \mathrm{m})$ time history

Figure 7: Ln of amplitude against cycle number

Figure 8: Single degree of freedom system with frictional damping

Figure 9: Drawing of mechanical damper

Figure 10 Mechanical damper attached to steady arm 


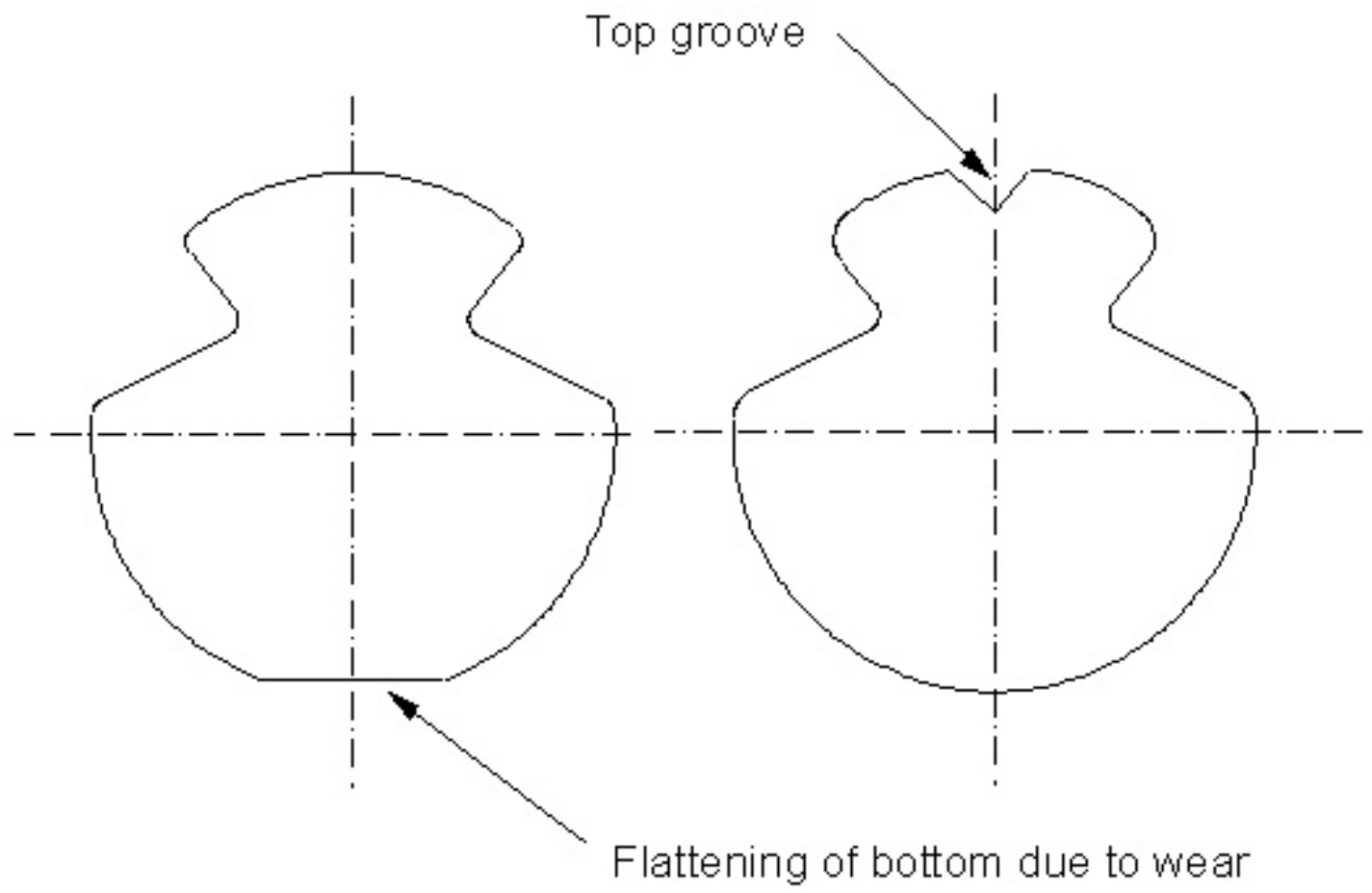

Figure 1: Contact wire cross section 


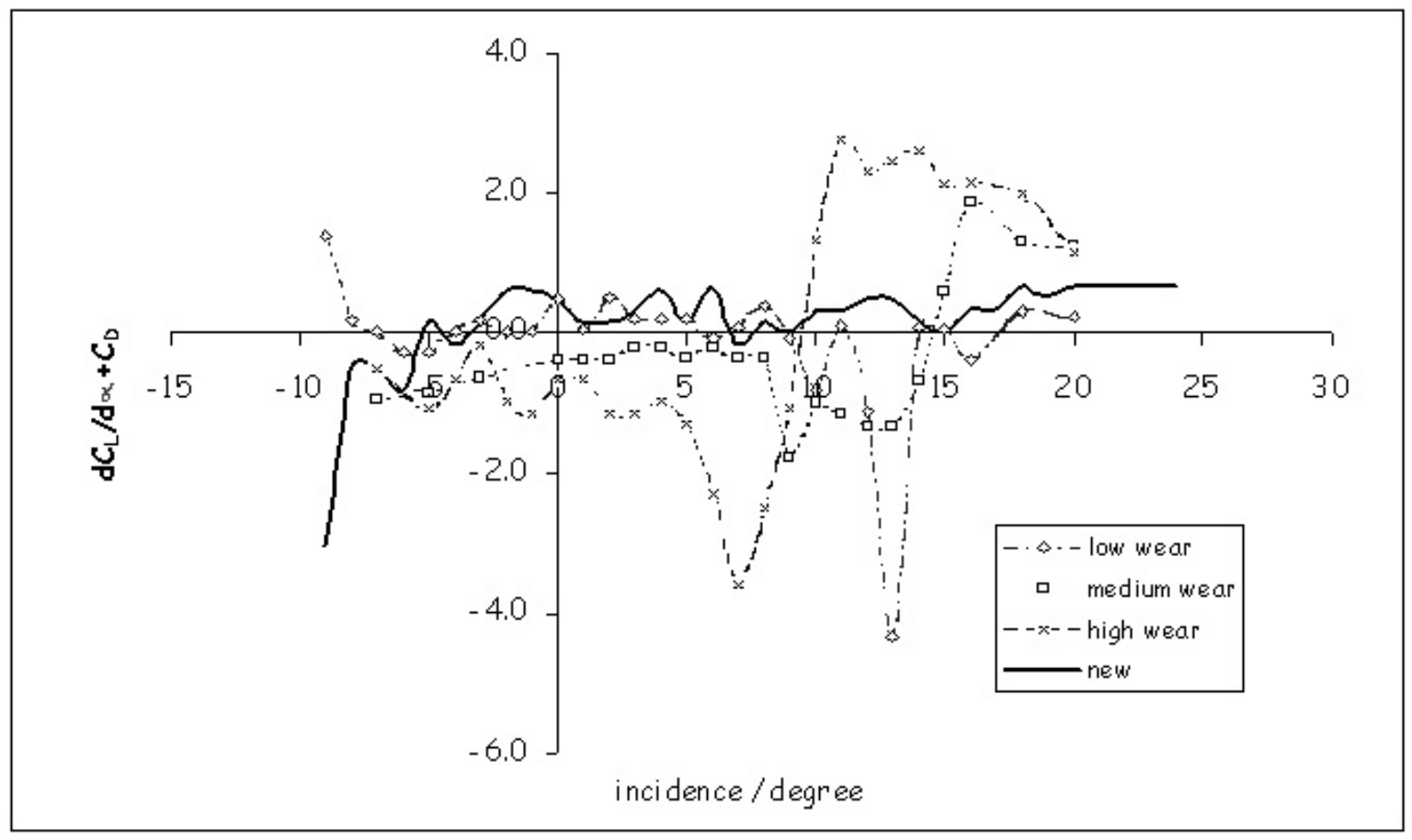

Figure2: Glauert-Den Hartog Criterion 


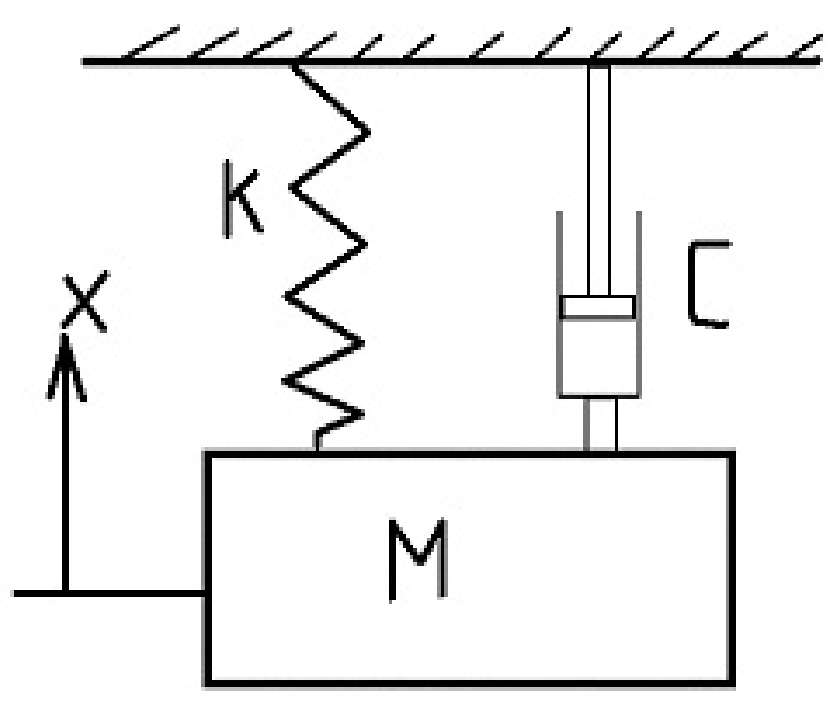

Figure 3: Single degree of freedom system 


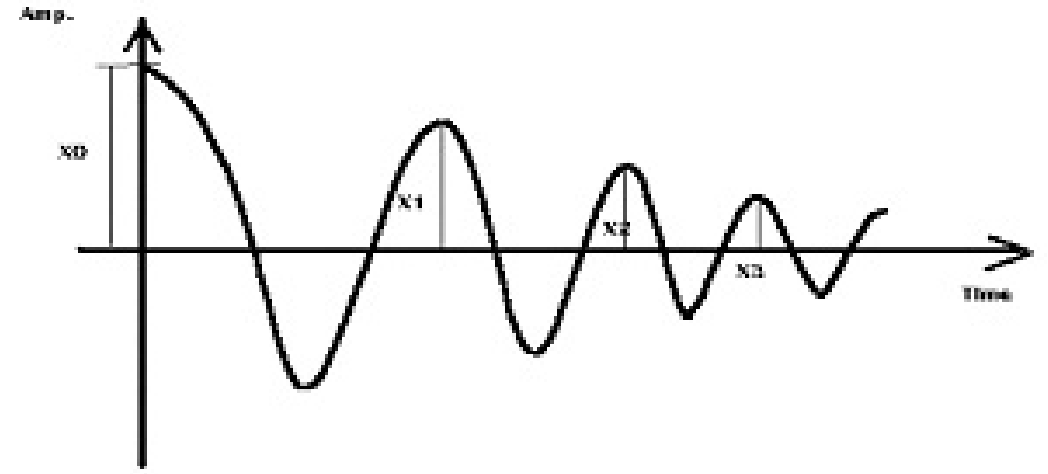

Figure 4: Typical vibration trace 


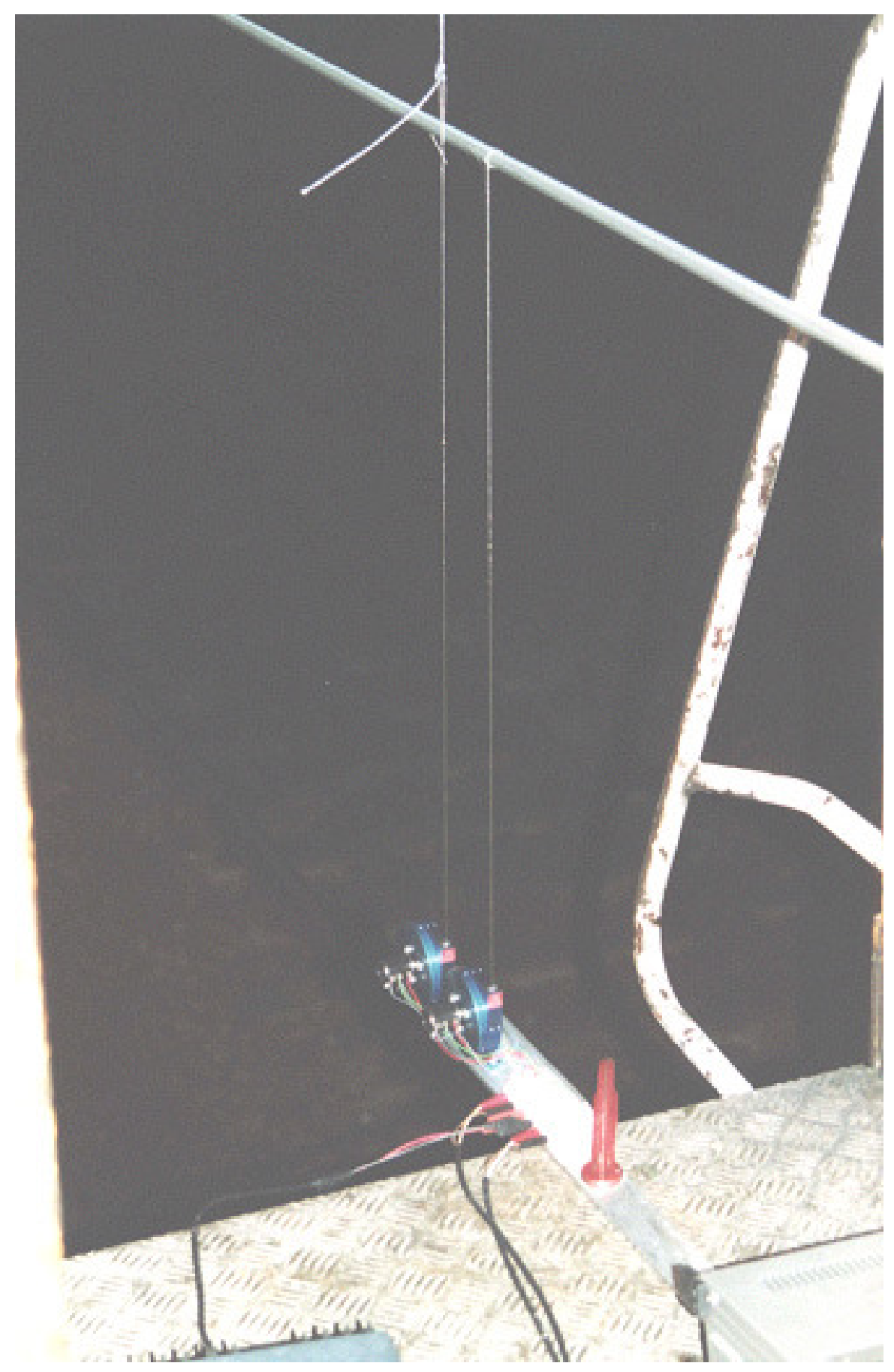

Figure 5: Displacement transducers connected to overhead wires 


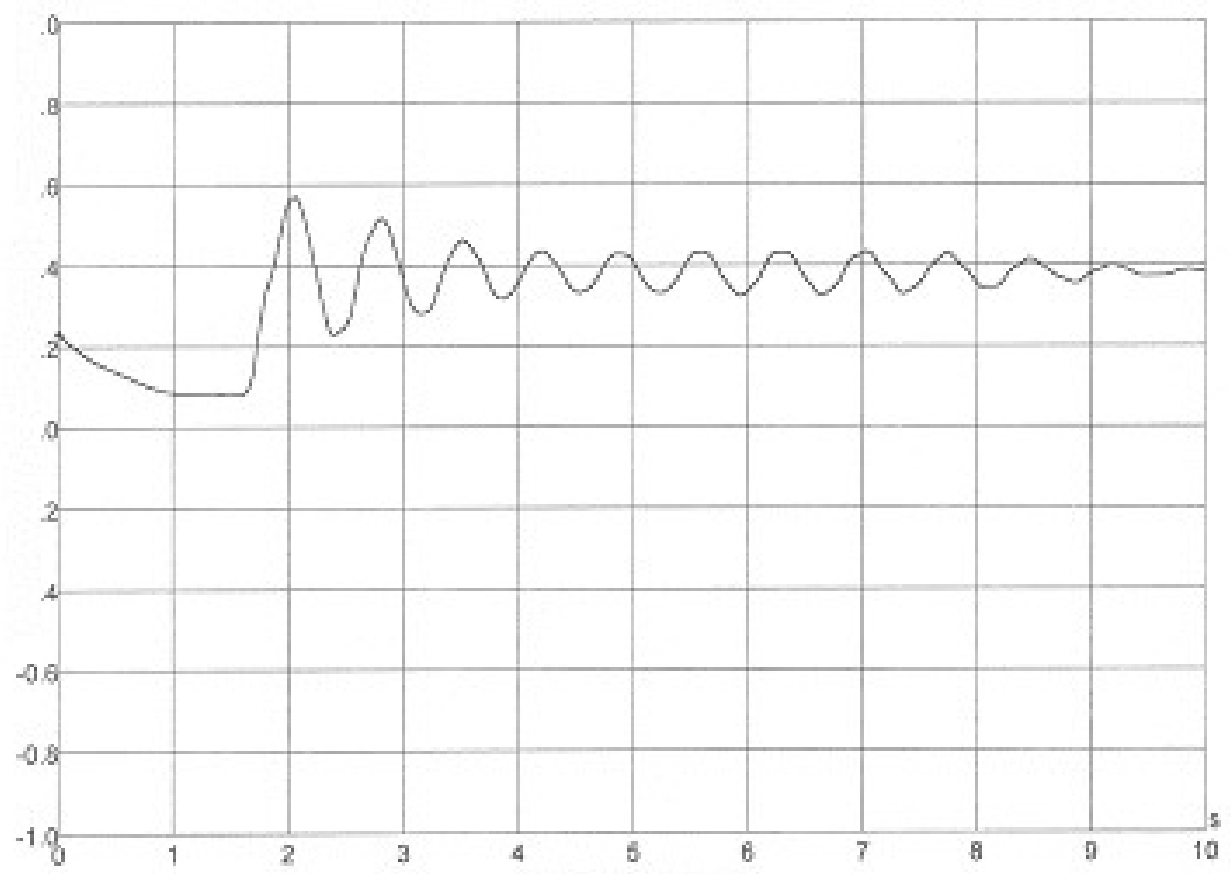

Figure 6: Displacement (/m) time history 
Conductor Damping

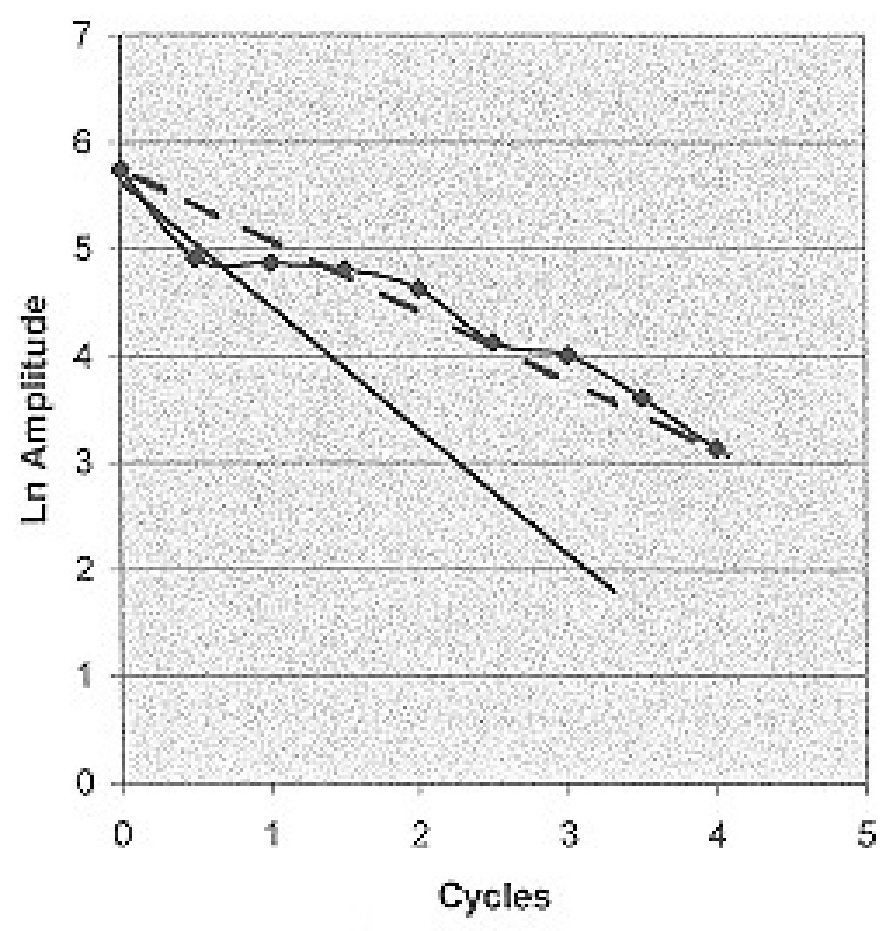

Figure 7: Ln of amplitude against cycle number 


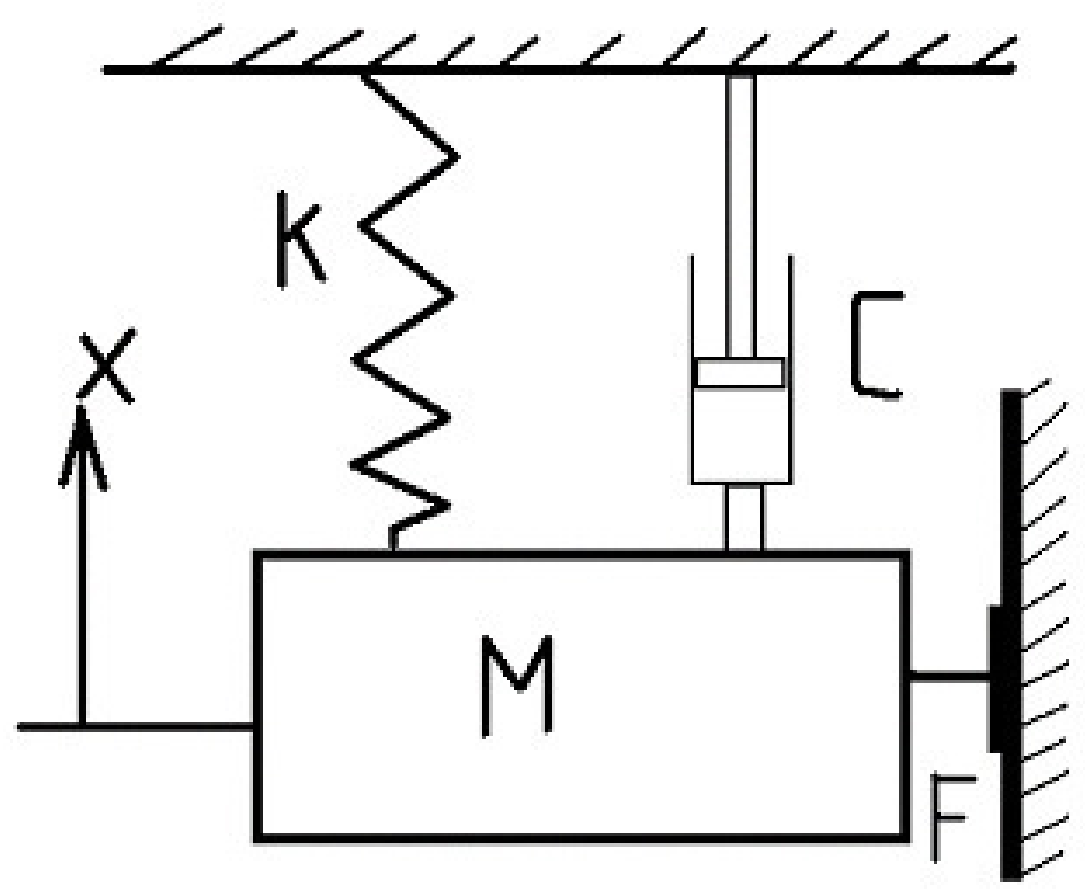

Figure 8: Single degree of freedom system with frictional damping 


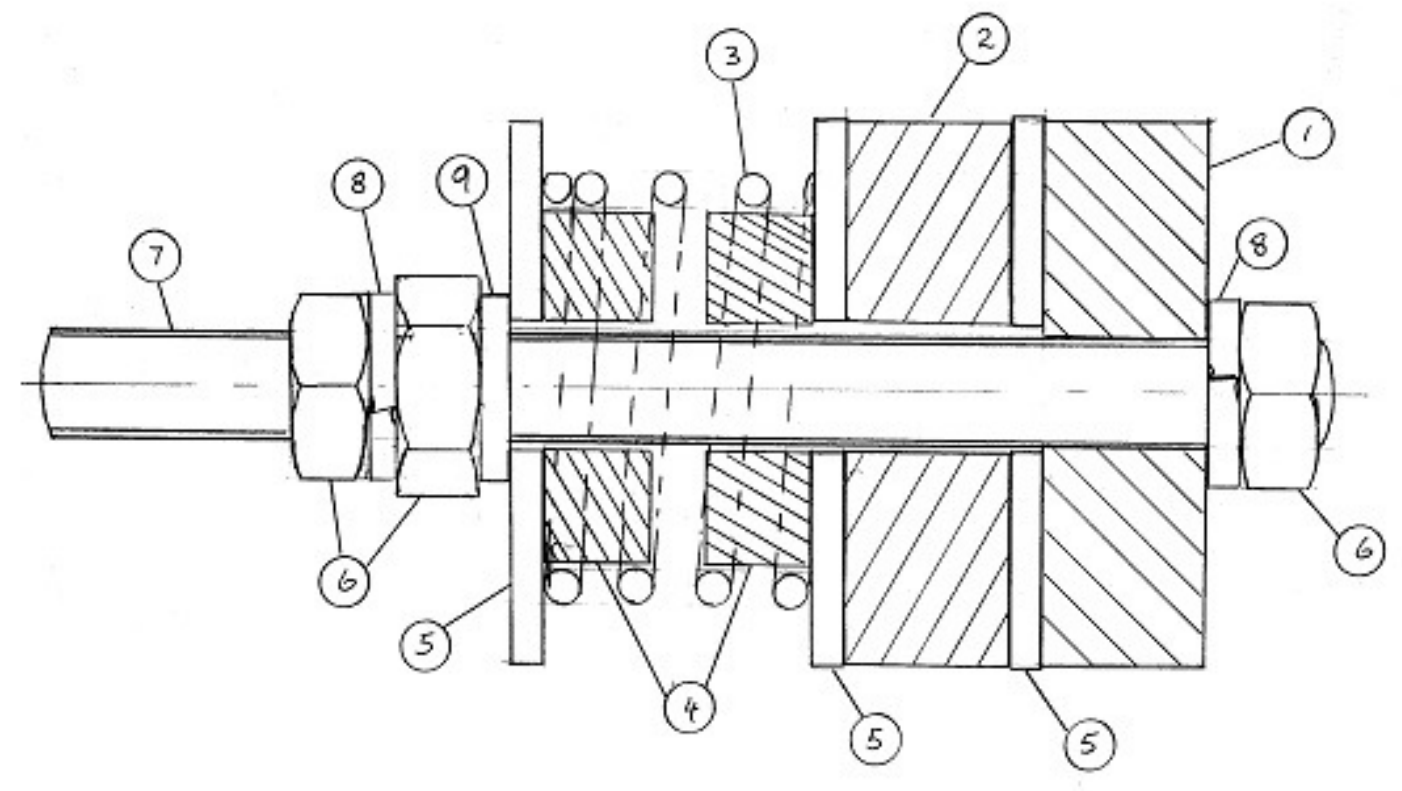

\begin{tabular}{|ll}
\hline 1 & Mast Bracket \\
\hline 2 & Arm Bracket \\
\hline 3 & Compression spring \\
\hline 4 & Nylon spring spacer \\
\hline 5 & Wear plate \\
\hline 6 & M10 nut \\
\hline 7 & M10 stud \\
\hline 8 & M10 locking washer \\
\hline 9 & M10 washer \\
\hline
\end{tabular}

Figure 9: Drawing of mechanical damper 


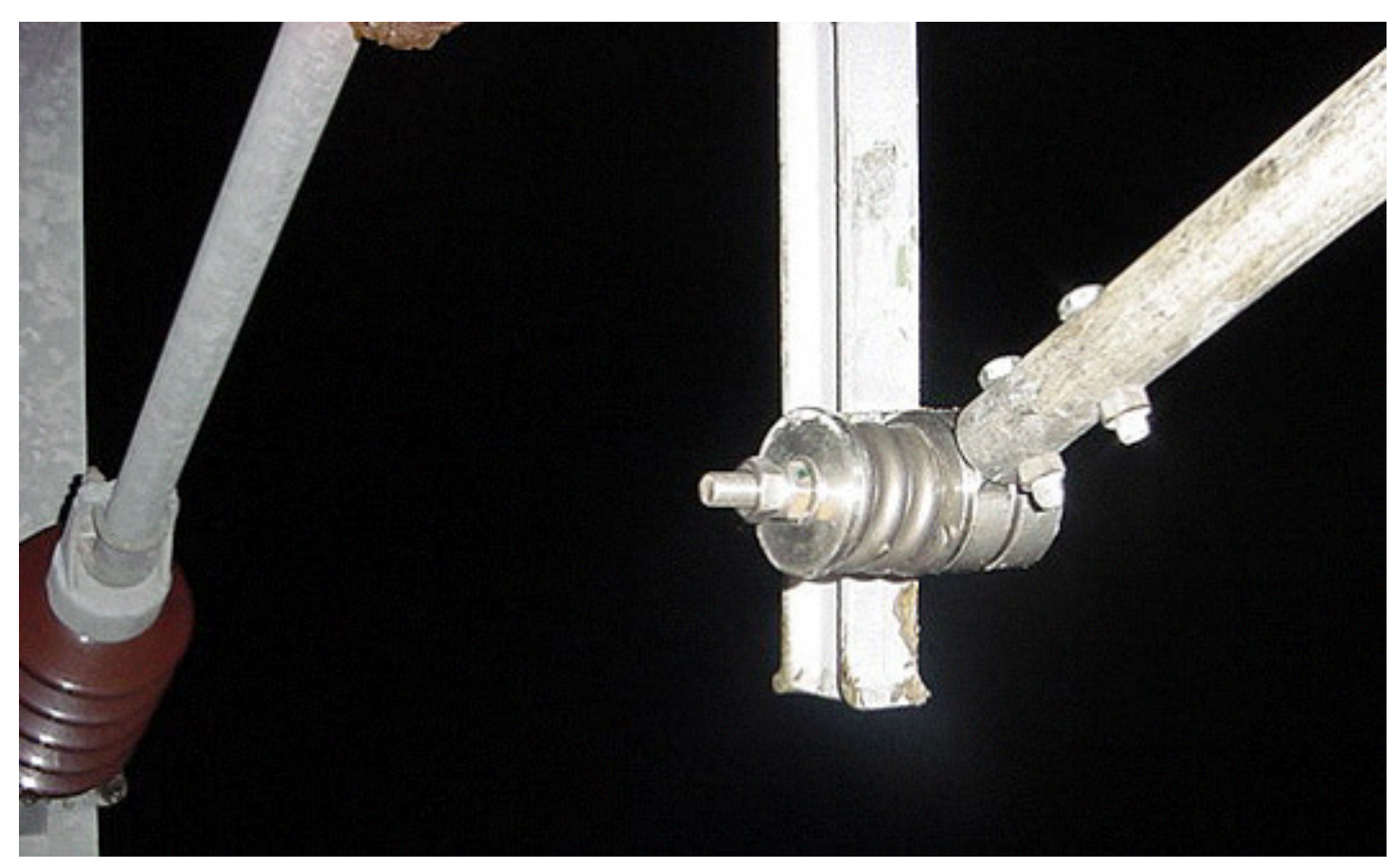

Figure 10 Mechanical damper attached to steady arm 


\section{List of tables}

Table 1 Measured natural frequency and damping ratio of the original system Table 2: Effect of friction on damping ratio

Table 3 Natural frequency and damping ratio system with increased damping

Table 4: Galloping onset speed, $\mathrm{U} \mathrm{m} / \mathrm{s}(\mathrm{mph})$, as a function of mechanical damping 


\begin{tabular}{|l|l|l|l|l|l|l|l|l|l|l|l|l|}
\hline & \multicolumn{6}{|c|}{ Frequency (Hz) } & \multicolumn{5}{|c|}{ Damping Ratio } \\
\hline Pos. & $\begin{array}{l}\text { Test } \\
1\end{array}$ & $\begin{array}{l}\text { Test } \\
2\end{array}$ & $\begin{array}{l}\text { Test } \\
3\end{array}$ & $\begin{array}{l}\text { Test } \\
4\end{array}$ & $\begin{array}{l}\text { Test } \\
5\end{array}$ & Ave & $\begin{array}{l}\text { Test } \\
1\end{array}$ & $\begin{array}{l}\text { Test } \\
2\end{array}$ & $\begin{array}{l}\text { Test } \\
3\end{array}$ & $\begin{array}{l}\text { Test } \\
4\end{array}$ & $\begin{array}{l}\text { Test } \\
5\end{array}$ & Ave \\
\hline 1 & 1.4 & 1.4 & 1.4 & 1.38 & - & 1.4 & 0.07 & 0.06 & 0.04 & 0.06 & - & 0.06 \\
\hline 2 & 1.37 & 1.35 & 1.36 & 1.55 & 1.33 & 1.39 & 0.05 & 0.05 & 0.07 & 0.1 & 0.04 & 0.06 \\
\hline 3 & 1.12 & 1.12 & 1.12 & 1.09 & - & 1.11 & 0.04 & 0.04 & 0.04 & 0.07 & - & 0.05 \\
\hline 4 & 1.15 & 1.17 & 1.18 & 1.17 & - & 1.17 & 0.03 & 0.02 & 0.03 & 0.02 & - & 0.03 \\
\hline 5 & 1.16 & 1.15 & 1.16 & 1.16 & 1.16 & 1.16 & 0.06 & 0.06 & 0.06 & 0.08 & 0.06 & 0.06 \\
\hline
\end{tabular}

Table 1 Measured natural frequency and damping ratio of the original system 


\begin{tabular}{|l|c|c|c|}
\hline & Viscous damping & Friction $11.3 \mathrm{~N}$ & Friction 22.6N \\
\hline Log Decrement $\sigma$ & 0.3135 & 0.493 & 0.905 \\
\hline Damping ratio $\zeta$ & 0.05 & 0.08 & 0.144 \\
\hline
\end{tabular}

Table 2: Effect of friction on damping ratio. 


\begin{tabular}{|l|c|c|c|c|c|c|c|c|c|c|c|c|}
\hline & \multicolumn{6}{|c|}{ Frequency $(\mathrm{Hz})$} & \multicolumn{5}{c|}{ Damping Ratio } \\
\hline Pos. & Test & Test & Test & Test & Test & Ave & Test & Test & Test & Test & Test & Ave \\
& 1 & 2 & 3 & 4 & 5 & & 1 & 2 & 3 & 4 & 5 & \\
\hline 1 & 1.4 & 1.37 & 1.43 & 1.43 & 1.44 & 1.41 & 0.07 & 0.08 & 0.08 & 0.08 & 0.08 & 0.07 \\
\hline 2 & 1.38 & 1.39 & 1.36 & 1.37 & 1.35 & 1.37 & 0.1 & 0.13 & 0.09 & 0.12 & 0.1 & 0.108 \\
\hline 3 & 1.13 & 1.14 & 1.13 & - & - & 1.13 & 0.12 & 0.12 & 0.11 & - & - & 0.117 \\
\hline 4 & 1.19 & 1.18 & 1.19 & 1.18 & 1.19 & 1.19 & 0.08 & 0.08 & 0.08 & 0.07 & 0.09 & 0.08 \\
\hline 5 & 1.18 & 1.3 & 1.1 & 1.3 & 1.3 & 1.24 & 0.09 & 0.09 & 0.07 & 0.09 & 0.09 & 0.086 \\
\hline
\end{tabular}

Table 3 Natural frequency and damping ratio system with increased damping 


\begin{tabular}{|c|c|c|c|c|}
\hline & Stickland $^{[1]}$ & Original & $\begin{array}{c}\text { Modified } \\
\text { Conservative }\end{array}$ & $\begin{array}{c}\text { Modified } \\
\text { Largest }\end{array}$ \\
\hline$\left(\frac{d C_{L}}{d \alpha}+C_{D}\right)$ & $\begin{array}{c}\zeta=0.1 \\
\omega=1.35\end{array}$ & $\begin{array}{c}\zeta=0.05 \\
\omega=1.4\end{array}$ & $\begin{array}{c}\zeta=0.095 \\
\omega=1.4\end{array}$ & $\begin{array}{c}\zeta=0.18 \\
\omega=1.4\end{array}$ \\
\hline-1 & $33.9(76)$ & $17.5(39)$ & $33.3(75)$ & $63.1(141)$ \\
\hline-2 & $16.95(38)$ & $8.8(20)$ & $16.7(37)$ & $31.6(71)$ \\
\hline-3 & $11.3(25)$ & $5.8(13)$ & $11.1(25)$ & $21.0(47)$ \\
\hline-4 & $8.48(19)$ & $4.4(10)$ & $8.3(19)$ & $15.8(35)$ \\
\hline
\end{tabular}

Table 4: Galloping onset speed, $\mathrm{U} \mathrm{m} / \mathrm{s}$ ( $\mathrm{mph}$ ), as a function of mechanical damping 